\title{
Representações sociais das famílias e dos usuários sobre participação de pessoas com transtorno mental ${ }^{*}$
}

\author{
SOCIAL REPRESENTATIONS OF FAMILIES AND USERS ABOUT \\ THEIR PARTICIPATION IN THE TREATMENT OF PERSONS WITH MENTAL DISEASES
}

\author{
REPRESENTACIONES SOCIALES DE LAS FAMILIAS Y USUARIOS SOBRE \\ SU PARTICIPACIÓN EN EL TRATAMIENTO DE PERSONAS CON TRASTORNO MENTAL
}

\begin{abstract}
Maria Salete Bessa Jorge', Ana Raquel Alves Ramirez², Consuelo Helena Aires Freitas Lopes ${ }^{3}$, Maria Veraci Oliveira Queiroz ${ }^{4}$, Vanessa Barreto Bastos ${ }^{5}$
\end{abstract}

\begin{abstract}
RESUMO
O objetivo da pesquisa foi investigar as representações sociais das famílias e dos usuários dos serviços de saúde mental acerca de sua participação no tratamento de pessoas com transtorno mental severo. $O$ estudo foi fundamentado na Teoria das Representações Sociais. Para a coleta de dados: teste de associação livre de palavras e entrevista com roteiro junto aos familiares e usuários de dois hospitais-dia, situados em Fortaleza-CE, Brasil. Conforme os resultados revelaram, os sujeitos da pesquisa consideram vantajoso o cuidado neste tipo de serviço e o apoio familiar essencial para o progresso no tratamento de pessoas com transtorno mental.
\end{abstract}

\section{DESCRITORES}

Saúde mental.

Transtornos mentais/terapia.

Família.

\begin{abstract}
This study was aimed at investigating the social representations of families and users of mental health services regarding their participation in the treatment of persons with severe mental disease. The study was based on the Theory of Social Representations. Data collection was carried out through the application of a free association of words test and an interview with a script with relatives and users of two dayhospitals in Fortaleza, State of Ceará. The results showed that the subjects of the research consider the care in this kind of service beneficial and think that family support is essential for progress in the treatment of persons with mental disease.
\end{abstract}

\section{KEY WORDS}

Mental health.

Mental disorders/therapy.

Family.

\begin{abstract}
RESUMEN
El objetivo de la investigación fue investigar las representaciones sociales de las familias y usuarios de los servicios de salud mental respecto a su participación en el tratamiento de personas con trastorno mental severo. El estudio estuvo fundamentado en la Teoría de las Representaciones Sociales. Para la recolección de datos: test de asociación libre de palabras y entrevista con una guía a los familiares y usuarios de dos hospitales-dia, situados en Fortaleza-CE, Brasil. Conforme los resultados reve-laron, los sujetos de la investigación con-sideran ventajoso el cuidado en este tipo de servicio y el apoyo familiar esencial para el progreso en el tratamiento de personas con trastorno mental.
\end{abstract}

\section{DESCRIPTORES}

Salud mental.

Trastornos mentales/terapia.

Familia.

\footnotetext{
* Extraído do Projeto de Pesquisa "Avaliação dos Serviços de Saúde Mental em Fortaleza: satisfação dos profissionais, usuários e familiares", financiado pelo CNPq em $2003{ }^{1}$ Enfermeira. Doutora em Enfermagem. Líder do Grupo de Pesquisa Saúde Mental, Família, Práticas de Saúde e Enfermagem. Pesquisadora do CNPq. Forateleza, CE, Brasil. masabejo@uece.br 2 Enfermeira. Graduada em Enfermagem pela Universidade Estadual do Ceará. Fortaleza, CE, Brasil. kelramires@yahoo.com.br ${ }^{3}$ Enfermeira. Doutorara em Enfermagem. Docente do Curso de Graduação em Enfermagem e Mestrado Acadêmico Cuidados Clínicos em Saúde da Universidade Estadual do Ceará (UECE). Fortaleza, CE, Brasil. consueloaires@yahoo.com.br ${ }^{4}$ Enfermeira. Doutora em Enfermagem. Docente do Curso de Graduação em Enfermagem e Mestrado Acadêmico Cuidados Clínicos em Saúde da Universidade Estadual do Ceará (UECE). Fortaleza, CE, Brasil. veracioq@hotmail.com ${ }^{5}$ Graduanda em Enfermagem da Universidade Estadual do Ceará (UECE). vbarreto32@hotmail.com
} 


\section{INTRODUÇÃO}

O Movimento de Reforma Psiquiátrica surgiu do desejo de mudar a situação de exclusão social e a precária assistência dispensada aos indivíduos com transtorno mental. Ele preconiza um atendimento em saúde mental que substitua o modelo hospitalocêntrico e possibilite a reinserção social, assim como a manutenção dos vínculos sociais e familiares dessas pessoas ${ }^{(1)}$.

Como mostra a literatura, a mudança da noção de doença para saúde mental implica a socialização do sofrimento mental, e passa a vê-lo como detentor da dimensão social, cultural e política, além da biológica. Neste contexto, a reabilitação psicossocial se alia a esta visão na medida em que ela é

[...] um processo de reconstrução, um exercício pleno de cidadania, e também de plena contratualidade nos três grandes cenários: habitat, rede social e trabalho com valor social(2).

No Brasil, a atual concepção política da reforma psiquiátrica foi construída a partir I Conferência Nacional de Saúde Mental ocorrida em 1987, quando foram formuladas propostas para reestruturação da assistência em saúde mental pautada no modo psicossocial de cuidar. Em 1992, com a II Conferência Nacional da Saúde, a reforma psiquiátrica se tornou política oficial do país e as famílias passaram a integrar as comissões representativas junto aos órgãos institucionais. Nesta ocasião, o Ministério da Saúde, pela Portaria $n^{\circ} 224$, propôs o atendimento à família em todos os serviços e a ampliação da rede de assistência mediante criação dos Centros de Atenção Psicossocial (CAPS), Núcleos de Atenção Psicossocial (NAPS), lares protegidos, serviços de urgências psiquiátricas, unidades psiquiátricas em hospitais gerais e hospitais especializados em psiquiatria(3).

No campo legislativo, destacamos o Projeto-lei $\mathrm{n}^{\circ}$ 3.657/89 do deputado Paulo Delgado, denominado Lei da Reforma Psiquiátrica, sancionado em 2001 com a aprovação da Lei $n^{\circ} 10.216$. Esta lei dispõe sobre os direitos e proteção dos doentes mentais, regulamenta a internação compulsória, contudo, contrariando o projeto original e atendendo a pressões dos grupos econômicos do poder, prevê a construção de uma rede de serviços alternativos ao modelo manicomial concomitante à construção de hospitais e à contratação de novos leitos.

Com a reforma, a modificação do modelo de assistência psiquiátrica levou a inclusão da família e, ao mesmo tempo, possibilitou-lhe desempenhar papel ativo nas comissões de controle social das políticas de saúde. Desse modo, a transformou em lugar estratégico e privilegiado das intervenções de reabilitação e reinserção psicossocial dos sujeitos com transtorno mental. No entanto, apesar dos avanços obtidos com este novo modelo, a integração da família no projeto terapêutico dos usuários ainda re- presenta um desafio que, na prática, não se fez acompanhar de infra-estrutura necessária à sua superação e consecução dos objetivos reabilitadores propostos pela reforma psiquiátrica.

Como evidenciado no dia-a-dia, os problemas decorrentes da convivência intensa da família com o parente acometido pelo transtorno mental estão associados a diversos fatores: o ambiente familiar, o padrão interacional do usuário e família, o despreparo da família para conviver com os egressos, a rejeição ao parente doente, a cidadania comprometida da pessoa com transtorno mental, a não-efetivação da reforma psiquiátrica, entre outros ${ }^{(4)}$.

De modo geral, é crescente a importância atribuída à participação e integração da família no projeto terapêutico da pessoa com transtorno mental. Tais participação e integração têm suscitado freqüentes discussões e estudos que abordam o tema tendo em vista a contextualização do cuidado em saúde mental a ser realizado fora dos espaços institucionais da psiquiatria. Desta forma, consideramos fundamental o grau de envol-vimento da família na vida do usuário a partir do qual podemos entender os limites e potencialidades das famílias para dar suporte às ações de reabilitação e inclusão social destas pessoas.

Com base no exposto, o objetivo operacional deste estudo é explorar as representações sociais da família e do seu parente acometido pelo transtorno mental em relação à participação da família no tratamento de usuários de hospital-dia.

\section{MÉTODO}

Estudo do tipo descritivo com eixo teórico na Teoria das Representações Sociais moscoviciana (TRS), assim definida:

[...] um corpus organizado de conhecimentos e uma das atividades psíquica graças às quais os homens tornam inteligível a realidade física e social, inserem-se num grupo ou numa ligação cotidiana de trocas, e liberam os poderes de sua imaginação(5).

\section{Local da pesquisa}

A pesquisa foi realizada em dois hospitais-dia: da rede de saúde mental do setor público e outro do setor privado, ambos situados na cidade de Fortaleza-CE. O hospital-dia, uma das propostas de assistência ao egresso de hospitais psiquiátricos, enquadra-se no sistema de semiinternação, investe na convivência familiar e aposta no maior distanciamento entre as internações e menor duração destas. Tais instituições propõem cuidar preservando os laços do usuário com familiares e comunidade de origem e fornecendo, para tanto, algum tipo de apoio às famílias, como, por exemplo, a realização de grupos de discussão com os familiares. 


\section{Sujeitos da pesquisa}

Os sujeitos eleitos para este estudo foram usuários de hospital-dia público com idade entre 21 e 60 anos e familiares dos usuários do hospital-dia privado que declararam viver diariamente com eles e que compareceram às reuniões de família no período do estudo, num total de 46 usuários e 28 familiares.

\section{Procedimentos éticos}

Em cumprimento das recomendações da Resolução do CNS $n^{\circ} 196$ de 10/10/1996(6), o projeto de pesquisa foi submetido ao Comitê de Ética da Universidade Estadual do Ceará e obteve parecer favorável em 23/08/2004. Ao abordar os informan-tes esclarecemos, previamente, o caráter sigiloso das informações coletadas para fins científicos, e que eles pode-riam desistir de participar da pesquisa, em qualquer etapa de sua execução, sem nenhum prejuízo financeiro ou no tratamento. Após dirimir as dúvidas dos informantes acerca dos procedimentos da pesquisa e assegurar-Ihes o anonimato, obtivemos sua permissão para coletar os achados mediante a assinatura do Termo de Consentimento Livre e Esclarecido.

\section{Instrumentos e procedimentos de coleta dos achados}

Utilizamos dois instrumentos de coleta de dados: O primeiro, o teste de associação livre de palavras, foi aplicado em 46 usuários e 28 familiares. Na ocasião solicitamos ao informante citar seis palavras associadas livremente às seguintes palavras, estímulos indutoras escolhidas aleatoriamente: Família; doença mental; saúde mental; hospital-dia; tratamento. O segundo instrumento, a entrevista com roteiro, foi realizada com cinco familiares de cada instituição pesquisada por meio das seguintes questões: O que é família para você? Como você percebe a doença e a saúde em sua vida? Fale sobre o tratamento em saúde mental. De posse dos achados, estes foram gravados e transcritos na íntegra pelo pesquisador.

Quanto aos dados obtidos pelo teste de associação livre de palavras, foram organizados manualmente, interpretados utilizando o método de estatística e apresentados em forma de tabelas. As evocações foram agrupadas por analogia, as semelhantes, e as diferentes categorizadas separadamente. Para a análise recorremos à exaustiva leitura das descrições, recortes de trechos de falas que representam os objetivos da pesquisa, elaboração de categorias e temas.

\section{RESULTADOS}

Como parte dos resultados da pesquisa foram elaboradas, inicialmente, representações pertinentes ao teste de associação livre de palavras tendo como fio condutor os estímulos indutores. No segundo momento nas entrevistas, procedemos à apreensão das representações focalizadas e multifacetadas, as quais foram interpretadas à luz da literatura e do eixo teórico das representações sociais.

\section{Família}

Para os usuários, o eixo central da representação é constituído pelos seguintes elementos: Família nuclear $(29,4 \%)$; Apoio e amor (27,7\%) e Família extensa (24,2\%). Os elementos periféricos encontrados foram estes: Comunidade e hospitalidade (5,2\%); Casa (4,6\%); Sofrimento e abandono (2,8\%); Separação e Paz (1,7\% cada um); Autoritarismo e Esperança (1,1\% cada um).

Os familiares apresentaram como elemento central predominante os termos: Amor (43,2\%); Família extensa (14,4\%); Atenção e apoio e Trabalho (12,3\% cada um) e Família nuclear (9,2\%). Os elementos periféricos foram representados pelos termos: Crianças e Lembrança $(4,1 \%$ cada um); Problemas (3\%); e Esperança e Escola (1\% cada um).

Na representação social de família o termo amor apareceu diversas vezes, demonstrando a forte conotação afetiva por meio de atenção e apoio. Além disso, muitos membros da família nuclear e extensa foram citados pelos participantes. Desse modo, o eixo central dessa representação foi semelhante nos dois grupos. Fornecer amor e apoio à família revelou uma associação. Tal associação decorre do fato de que dispensar esse suporte afetivo aos seus membros é uma de suas atribuições, o próprio cuidado é uma manifestação de afeto e, portanto, tem a capacidade de fortalecer os vínculos e gerar bem-estar ${ }^{(7)}$.

\section{Hospital-dia}

Conforme observamos, o eixo central das representações dos usuários foi o seguinte: Tratamento (34,2\%); Paz e amor (25\%); Ocupação $(19,4 \%)$ e Recuperação $(15,7 \%)$. Quanto à periferia, compôs-se das palavras: Transtorno Mental (4,6\%) e Fé $(0,9 \%)$.

No referente ao centro da representação social dos familiares, foi expresso por: Tratamento (22,5\%); Família, acolhimento e Ressocialização ( $17,7 \%$ cada um). A periferia foi representada pelas palavras: Atividades (8\%); Recuperação (6,4\%); Paz e convívio e Doença $(3,2 \%$ cada); Solução parcial e Serviço substitutivo (1,6\% cada um).

Como identificado, o termo hospital-dia contou com uma freqüência elevada de evocações da palavra tratamento. No entanto, ainda não há uma padronização dos hospitais-dia em relação ao tratamento e às atividades 
oferecidas, tendo em comum a internação em regime parcial e a proposta de ser uma alternativa à internação fechada(8).

Apesar desta evidência, tanto os usuários quanto suas famílias demonstraram ter uma visão positiva sobre esta instituição e afirmaram acreditar que ela possa trazer benefícios para seus clientes.

\section{Doença mental}

Como núcleo central da doença mental, os usuários apresentaram loucura $(40,3 \%)$ o qual associado aos termos Sofrimento (12,5\%); Nervosismo e Reabilitação social $(9,6 \%$ cada um) e Tratamento $(8,6 \%)$ compõem o eixo central. Já a periferia é formada por: Internação (4,8\%); Família e Preconceitos (3,8\% cada um); Solidão e Hospital-dia ( $2,8 \%$ cada um) e Cidadania $(0,9 \%)$.

Para os familiares, Nervosismo e sofrimento $(44,8 \%)$ constituem o elemento central predominante e, juntamente, com Doença (14,2\%); Paciência e Tratamento (8,1\% cada um) formam o eixo central. Quanto aos núcleos periféricos da representação, são constituídos pelas palavras: Diferente/Anormal (6,1\%); Fé, Pena e fragilidade e Família extensa ( $4 \%$ cada uma); Recuperação, Ociosidade e Preconceito ( $2 \%$ cada uma).

A representação social dos usuários e familiares acerca da loucura teve como elemento central predominante doença e nervosismo e sofrimento, nessa posição, respectivamente. Os sentimentos de pesar e angústia foram citados por ambos, mas manifestou-se de forma mais clara e contundente no modo de ser da família de pessoas com transtorno mental, corroborando a literatura ${ }^{(9)}$. Contudo, referências à reabilitação social, ao hospital-dia, à recuperação e ao próprio tratamento revelam uma maneira diferente de ver o transtorno mental que reflete as mudanças ocorridas na atenção psiquiátrica.

\section{Saúde mental}

Como eixo central das representações dos usuários foram expressas as palavras: Recuperação (28\%); Tratamento (20,7\%); Amor e convívio (14,6\%); Esperança (10,9\%) e Trabalho (8,5\%). Os elementos periféricos foram: Diversão (4,8\%); Internação (3,6\%); Transtorno mental e Família (2,4\% cada uma) e Medo, Tristeza e Hospital-dia (1,2\% cada uma).

No eixo central da representação dos familiares encontram-se as palavras: Saudável (23\%); Recuperação (17,9\%) e Tratamento (15,3\%). O eixo periférico esta representado por: Discernimento, Paz, Atividade e Alegria (7,6\% cada uma); Hospital-dia (5,1\%); Família extensa, Problemas e Viver (2,5\% cada uma).

Acerca do termo saúde mental, segundo percebemos, era bastante conhecido e os usuários vivenciavam um processo de busca pela própria saúde mental. Ainda como percebemos, familiares e seus parentes com transtorno psíquico deixaram transparecer a expectativa de melhora mediante o tratamento em hospital-dia.

É inegável a importância da família conhecer as reais possibilidades de melhora do seu paciente em tratamento, pois, às vezes, existe esperança na recuperação e cura, mesmo em meio a um contexto desfavorável ${ }^{(10)}$. Diante desta situação, as pessoas precisam ser orientadas para saber que a reabilitação significa autonomia e que esta depende das condições de cada um. Portanto, pode ou não acontecer para todos.

Mas essas condições envolvem a cidadania dos grupos marginalizados, o acesso à produção e partilha das riquezas sociais e oportunidades de participação da pessoa com transtorno mental na vida em sociedade.

\section{Tratamento}

Para os usuários, Atenção e apoio (47,6\%) e Amor $(25,7 \%)$ formam o eixo central. Os elementos periféricos foram compostos por: Família nuclear (7,6\%); Família extensa (6,6\%); Desamparo (4,7\%); Tratamento $(3,8 \%)$ e Lar, Dinheiro e Educação (0,9\% cada um).

Para os familiares, o eixo central é representado pelos seguintes termos: Essencial para o tratamento $(49,1 \%)$; Apoio e amor (42,6\%), enquanto no eixo periférico: Família nuclear $(6,5 \%)$ e Tratamento $(1,6 \%)$.

Os usuários e os familiares acentuam, como eixo central da representação acerca do tratamento, a participação da família com ênfase para o seu papel afetivo, relacionado ao interesse e estímulo. Segundo observamos, existe um consenso significativo entre os familiares sobre a influência preponderante do grupo familiar para o progresso no tratamento do usuário.

Como mostram alguns autores, o familiar é um parceiro singular e fundamental para o cuidado ao doente mental. Contudo enfatizam a necessidade de ações que potencializem essa relação e forneçam suporte a ele $\mathrm{e}^{(10) .}$

Além das representações sociais elaboradas no momento da aplicação do teste de associação livre de palavras, conforme percebemos, os 10 informantes entrevistados contemplam as representações elaboradas em relação ao cuidado do sujeito com transtorno mental cuja família é considerada como suporte de atenção, destacando-a como fundamental. Também mencionaram a família ausente.

Grande parte dos entrevistados reconhece o valor da contribuição da família na recuperação de seus parentes acometidos pelo transtorno mental. Como fonte de ajuda, foram citados, sobretudo, o pai e a mãe, membros da família nuclear.

Sobre a ausência da família no contexto do cuidado, os familiares entrevistados expressaram-se com pesar. 
Segundo relataram, os parentes com transtorno mental com quem convivem percebem a falta de interesse de alguns familiares em relação a eles. Isto os entristece.

Eu acho que a família discrimina. [...] E ele senei muito a falta da família. É o maior problema dele, porque se a família estivesse dando aquele aconchego eu acredito que ele estava melhor do que ele está (Familiar 5).

$\mathrm{Na}$ opinião dos entrevistados, porém, existem razões para esse comportamento por parte de alguns membros da família. Estas foram associadas, principalmente, à falta de tempo. Outros fazem referência a sentimentos de preconceito e estigma muito fortes entre os demais familiares.

Também foram elaboradas representações sobre o sofrimento e ônus familiar e o cuidar pela família.

Como é notório, a doença mental exerce um forte impacto sobre a vida familiar. Seu diagnóstico é acompanhado por momentos de incerteza e perplexidade. Conforme o grau de parentesco, ter uma pessoa com transtorno mental na família é vivenciar sentimentos de tristeza, vergonha, raiva, impotência e ansiedade. No destaque extraído da entrevista sobressaem sentimento de culpa e sofrimento em face da doença.

Quando ele começou com esse problema eu senti muito. A gente como mãe ver um filho que nasceu sadio ficar numa situação dessa. Às vezes eu me culpo, mas - meu Deus

- eu tinha necessidade de trabalhar [...] (Familiar 5).

De acordo com a literatura, o sofrimento é o impacto de todas as pressões da vida sobre um membro da família e o ônus está limitado ao impacto do parente que tem uma doença mental ${ }^{(11)}$. Existe o ônus é objetivo e subjetivo. $O$ ônus é objetivo quando se relaciona ao comportamento e seus efeitos adversos sobre a família, além da carência de suporte e dos gastos com a doença. Já o ônus subjetivo é a sensação da pessoa estar sobrecarregada, é algo individual, e não está fortemente vinculado com fatores do ônus objetivo.

Ainda de acordo com a literatura, o cuidado familiar é um sistema amplo dirigido à pessoa enferma e aos outros integrantes da família. De modo geral, a mulher, geralmente, é o centro deste processo de cuidado. Ele é uma produção cultural e demanda participação de cada membro da família. Nele se agrupam crenças, valores, preconceitos, e é, sobretudo, fundado nas percepções de saúde e doença da família(12).

Ao avaliarmos a situação, um ponto sobressai, qual seja: a exigência de se retornar o doente para casa, sem considerar as condições e habilidades de ambos para essa vivência que pode ser tão negativa quanto sua exclusão social.

Neste contexto, as representações sócia afetivas vêm à tona como expressão do amor.
Como sabemos, o desenvolvimento afetivo é uma das funções básicas da família. O afeto tem a ver com amar e ser amado; é uma necessidade psíquica do ser humano. Conforme a visão dos entrevistados, a família se caracteriza por fornecer carinho, companhia e incentivo aos seus membros.

A família é muito importante porque um acolhe o outro. Porque no momento em que um abandona, aquela pessoa se sente só, se entrega à tristeza, à melancolia. [...] sozinha, ela vai cada vez se afundando mais (Familiar 8).

Segundo os informantes expressaram, a que família deve demonstrar esse afeto e apoio como forma de estimular o parente a não se deixar dominar pelas dificuldades decorrentes da experiência com o transtorno mental.

Para a realização de um verdadeiro projeto terapêutico, a família e os elementos da comunidade precisam se envolver neste processo ${ }^{(13)}$. Por exemplo, se a pessoa com transtorno mental não puder tomar as medicações em horários certos, estabelecer relações com os outros, voltar aos serviços de saúde para consultas ou para outras atividades, alguém deverá auxiliá-la. Este alguém pode ser um familiar, um vizinho ou uma pessoa do próprio serviço.

Como mencionado por alguns autores, as relações interpessoais do sujeito como representações de trocas afetivas com pacientes com transtorno mental encontramse prejudicadas e essa problemática mantém estreita ligação com os sintomas primários, ou seja, aqueles causados diretamente pela doença ${ }^{(11)}$.

É preciso, pois, trabalhar a reabilitação. Esta propõe auxiliar o usuário a ter condições para efetivar trocas afetivas positivas. A instituição familiar, a comunidade e o serviço de saúde, no caso, o hospital-dia, são propícios para isso. Conforme identificamos, os entrevistados mostraram-se favoráveis ao contato e à construção de vínculos entre pessoas com transtorno mental e, destas, com outras pessoas.

Quanto ao relacionamento sem ser aqui do hospital-dia, ele tem relacionamento com os vizinhos, vai à casa dos parentes [...] ele melhorou muito com esse contato com as pessoas (Familiar 5).

As habilidades sociais são essenciais para vivermos em comunidade e a proposta de reabilitação psicossocial relaciona-se ao preparo do usuário para essa convivência e inclui a aceitação de si mesmo como sujeito com transtorno mental. Vale salientar que a solidão e o isolamento social dos sujeitos com transtorno mental são condições que decisivamente contribuem para a emergência dos sintomas secundários presentes nos transtornos mentais severos em resposta ao seu tratamento ${ }^{(11)}$.

Nas falas das famílias evidenciamos representações relacionadas à cura na saúde mental, para se referir à remissão de sintomas graves e à mudança significativa 
no estado clínico do paciente. Outros, porém, acreditam em uma cura total, mesmo contrariando as perspectivas médicas. Esta é uma situação delicada, pois lidamos com o desejo da família configurado numa perspectiva que talvez jamais se concretiza e isso pode ocasionar frustração com o tratamento.

Foi aqui que ela veio ficar boa, que veio se recuperar com a ajuda e a assistência deles aqui e com a minha e a dela. [...] Eu acredito com a ajuda de Deus que ela vai voltar para a faculdade dela e que eu vou ver ela se formar. Ela diz: Mãe, mas os médicos dizem lá que quem tem depressão não fica boa. $E$ eu digo que eles não deviam dizer isso porque a pessoa já tá nervosa fica mais nervosa. Eu digo: - Depende do caso minha filha, quando a pessoa é idosa, já tem idade, tudo bem, mas você que é bem novinha tem que ficar boa (Familiar 1).

Neste contexto, a representação da cura está relacionada às atividades de reabilitação No entanto, não se trata de fazer o usuário voltar ao estado anterior, entendido como cura e adaptação, mas de fortalecer o seu poder de contratualidade social, propiciando, com isto, o mais alto grau de funcionamento e autonomia possível. Esta concepção permite aos familiares, ao conviver com a diferença, construir expectativas realistas quanto à recuperação do parente com transtorno mental, respeitando-lhe os limites e incrementando suas potencialidades.

Eu creio que elas ainda podem viver suas vidas normal, não normal como no começo da sua juventude, da sua adolescência, mas normal da vida agora pra frente, um outro tipo de vida, um outro tipo de negócio, de renda, tudo outro tipo, seguindo as condições delas (Familiar 8).

Outro ponto relevante representado foi o hospital-dia, despertando em familiares e usuários sensações de bemestar e aceitação. Os entrevistados demonstraram uma percepção positiva acerca da relação entre o hospitaldia e sua clientela.

Eu acho que no futuro vai ter um grande retorno, porque no hospital-dia eles são bem aceitos, são bem atendidos (Familiar 2).

Assim, como outros serviços substitutivos, o hospitaldia precisa ter um ambiente terapêutico que estimule a recuperação da saúde. Este ambiente deve possuir uma estrutura física adequada para que a permanência dos familiares e usuários e dos próprios profissionais seja agradável|(14).

Como observamos, os aspectos físicos dos dois hospitais-dia visitados eram semelhantes, locais amplos, arborizados, com painéis e cores alegres. Nestes, os aspectos psicológicos e sociais trabalhados se refletem no clima de paz e amizade. $O$ espaço de acolhimento oferecido pelo hospital-dia é extensivo à família. Quanto à forma mais citada, pela qual se dá o vínculo família-hospital-dia, foi a realização de grupos de família. Esse grupo é, comumente, chamado de reunião de família. Nos locais estudados acontece uma vez por semana e conta com a presença de profissionais e familiares. As reuniões de família decorrem da necessidade de conhecermos o cliente no seu convívio familiar e também de fornecer às famílias algum suporte para a superação das dificuldades inerentes à interação com o usuário no domicílio.

Nos discursos dos familiares, a troca de informações com a equipe foi apontada como característica da modalidade de atenção do hospital-dia.

Nós que estamos participando das reuniões damos informações pra tirar alguma dúvida com respeito ao paciente que necessita de tratamento (Familiar 2).

Os membros da família que mantêm contato diário com o paciente são capazes de perceber alterações no comportamento e no desenvolvimento de atividades. Aqueles mais informados podem oferecer aos profissionais dados suplementares e, às vezes, mais confiáveis que o próprio paciente ${ }^{(15)}$.

Na opinião dos entrevistados, a participação de familiares nas reuniões de família é importante para a adesão do usuário ao tratamento.

A família participa em fazer essa reunião, troca de idéia com os médicos [...] o próprio paciente olha que a família está tendo aquela associação com os médicos. Então, ele mesmo fica acreditando que é bom pra ele (Familiar 6).

Nos achados, também foram apontadas as dificuldades enfrentadas pelas famílias manterem maior contato com os serviços, conforme requisitado pelos hospitaisdia. Neste novo contexto, as famílias têm sua participação solicitada tanto em casa quanto no serviço de saúde.

É muito fácil julgar, sair exigindo que a pessoa venha. Por exemplo, existe uma reunião aqui que é num dia de semana, querem que venha cada filho. Não vai vir nunca. Às vezes assim [...] a pessoa pensa que não quer dar atenção, mas não é isso não. As empresas hoje em dia, você não pode tá faltando (Familiar 3).

Como ressalta a fala, os familiares são afetados pela doença e, ao mesmo tempo em que tentam superar seus próprios problemas estão sendo chamados, a ajudar no cuidado ao doente mental. A oferta de serviços substitutivos deveria trabalhar o cuidado ao doente e à família, porém na maioria dos casos isso não é uma realidade ${ }^{(13)}$.

Ainda segundo a mesma fonte, de forma geral, o relacionamento das famílias com os doentes mentais se intensifica quando há a presença de doença mental em um dos seus membros ${ }^{(13)}$.

Quanto a terapia medicamentosa, segundo o modelo de habilitação psiquiátrica, não visa o controle de sintomas, mas seu uso de forma apropriada, havendo tolerância para alguns sintomas da doença. Ela não deve ser usada isoladamente, ou seja, pode ser associada. Por exemplo, a terapia com a atividade, como acontece nos hospitais-dia estudados. 
Muitos pacientes psiquiátricos tornam-se apáticos. Contudo, a falta de atividade entre eles tem efeito negativo no comportamento. Portanto, praticar alguma atividade é um ponto importante do tratamento em saúde mental e constitui uma terapia

[...] O que é terapêutico, na atividade, não é só manter-se ocupado, mas o fato de que as pessoas possam ocupar outros papéis, além do doente ${ }^{(14)}$.

A terapia pela atividade se divide em dois tipos: A ocupacional, que propicia o exercício de maneiras mais criativas de se expressar pelo desenho e pela música, por exemplo, e de se relacionar com os outros; a recreativa, que tem metas semelhantes à anterior e pode ser implementada mediante práticas esportivas, passeios e festas.

São perceptíveis os benefícios da terapia recreativa, os quais ocorrem durante os preparativos na atividade em si e depois de concluída, com as relações criadas. [...]. Por meio da atividade em grupo, os usuários desenvolvem sua capacidade de relacionamento ${ }^{(14)}$.

[...] a gente vê como se fosse uma terapia que ela tá fazendo, na verdade tem ajudado muito a ela, porque depois que ela começou a vir, a participar dessas reuniões que tem aqui, participar do grupo, da sociedade daqui de dentro mesmo, ela já tá sendo outra pessoa [...] (Familiar 3).

Na percepção dos familiares, o fato de alguém estar vinculado a uma instituição psiquiátrica implica preconceito em muitas pessoas e isso constitui uma barreira determinante de sofrimento na vida de alguém com transtornos mentais.

Têm preconceito, porque eles dizem que é louco. [...] É tanto que ela não quer que eu diga que ela tá no hospital. Ela tem medo de não arrumar um namorado, porque ninguém vai querer mais ela [...] Ela diz: - será que alguém vai me querer pensando que eu sou louca? Porque tem preconceito, é tanto que as amigas dela é muito difícil aparecerem lá em casa (Familiar 1).

Durante anos, o sujeito com transtorno mental foi visto como incapaz e perigoso, características que compõem seu estigma social. Apesar das mudanças de conceitos e práticas, essa imagem ainda predomina nas representações dos familiares. A nosso ver, esta concepção se deve, em grande parte, ao desconhecimento das pessoas acerca deste tema. Muitos conhecem apenas os serviços psiquiátricos disponíveis e só têm contato com a problemática desta clientela quando um parente ou conhecido passa por essa situação.

Muita gente não sabe nem o que é o hospital-dia, pensa que é hospital para doente mental completamente louco [...] já as pessoas da família que já vieram aqui, até amigo, depois que vem, vê que não era bem daquela forma (Familiar 3).

Para superar este preconceito, cabe às instituições de saúde mental, incluindo o hospital-dia, a tarefa de trans- formar a visão socialmente compartilhada acerca do transtorno mental. Neste intuito, é preciso implementar ações assistenciais que promovam a integração social da sua clientela e minimizem os efeitos do preconceito na vida do usuário. Infelizmente, esse processo de desmistificação da loucura ainda tem um longo caminho a percorrer até dissipar concepções errôneas presentes no imaginário popular.

\section{CONSIDERAÇÕES FINAIS}

Conforme observamos, a instituição familiar é percebida pelos sujeitos da pesquisa como peça fundamental ao portador de transtorno mental. No modelo da reabilitação psicossocial o tratamento objetiva ampliar a autonomia do paciente. Contudo, mesmo assim, existem vantagens no envolvimento dos familiares. Estes, ao compreenderem a terapêutica e consentirem em colaborar com ela, estão mais propensos a cuidar de forma adequada.

Entretanto, nem todos os usuários contam com familiares dispostos ou capazes de ajudá-los. Ademais, os parentes mais próximos podem ficar sobrecarregados por não terem com quem dividir essa responsabilidade. Outro aspecto relevante é o desgaste emocional da família ao enfrentar o comportamento gerado pela doença e seus efeitos na vida de indivíduo e do grupo como um todo.

Para os sujeitos da pesquisa, a família foi representada, predominantemente, como fonte de afeto e apoio. $O$ hospital-dia foi caracterizado como um local de tratamento e acolhimento, além de se relacionar a ocupação e a laços de amizade. A partir das representações apreendidas notamos que o sofrimento causado pelo transtorno mental ainda é algo marcante na vida dos envolvidos. Todavia, tanto familiares como usuários demonstraram acreditar nas possibilidades de progresso advindas do atendimento nesse tipo de serviço. Assim, a saúde mental apareceu vinculada à recuperação e ao tratamento.

Na percepção de ambas as populações, a família participa do cuidado do parente com transtorno mental, fornecendo amor e incentivando a adesão ao tratamento. Também, segundo afirmaram, a associação entre a instituição familiar e o hospital-dia foi considerada necessária para o processo de reabilitação dos clientes.

Apesar das mudanças conceituais na psiquiatria e nos tratamentos para a doença mental, a sociedade, maneira geral, ainda possui uma visão distorcida sobre ela. Como alguns representantes das famílias comentaram, seus doentes são vítimas de preconceito. Isto ocorre mesmo sendo essa instituição bastante diferente dos antigos manicômios. Carregar o estigma de ser doente mental é um fator a mais de sofrimento na vida dessas pessoas e interfere nas oportunidades de envolvimento social. Mas esse posicionamento pode ser reforçado ou até causado pela desinformação. 
Conforme apreendemos, nos aliarmos à família é uma forma de garantir a continuidade do cuidado. Assim, enfatizamos a importância de momentos como as reuniões de família, pois elas ensejam, maior integração entre o grupo familiar e o hospital-dia. Nelas os famili-

\section{REFERÊNCIAS}

1. Silva MRS, Bernardi Neto C. A convivência do velho e do novo num contexto que preconiza a desinstitucionalização da doença mental. Texto Contexto Enferm. 1999; 8(2):377-88.

2. Saraceno B. Reabilitação psicossocial: uma estratégia para a passagem do milênio. In: Pitta AMF, organizadora. Reabilitação psicossocial no Brasil. São Paulo: Hucitec; 1996. p. 13-8.

3. Costa-Roza A, Luzio CA, Yatsui S. As conferências nacionais de saúde mental e as premissas do modo psicossocial. Saúde Debate. 2001;25(58):12-25.

4. Waidman MAP, Elsen I, Moreira JK. Fatores que interferem na desinstitucionalização e reinserção do portador de transtorno mental na família. Arq Apadec. 2004;8 Supl 1:21-8.

5. Moscovici S. A representação social da psicanálise. Rio de Janeiro: Zahar; 1978.

6. Conselho Nacional de Saúde. Resolução n. 196, de 10 de outubro de 1996. Dispõe sobre diretrizes e normas regulamentadoras de pesquisas envolvendo seres humanos. Bioética. 1996;4(2 Supl):15-25.

7. Elsen I. Cuidado familial: uma proposta inicial de sistematização conceitual. In: Elsen I, Marcon S, Santos MR. O viver em família e sua interface com a saúde e a doença. Maringá: EDUEM; 2002. p. 13-24.

8. Lima MC, Botega NJ. Hospital-dia: para quem e para quê? Rev Bras Psiq. 2001;23(4):195-9. ares compartilham experiências e se apóiam mutuamente, conversam com os profissionais e recebem deles orientações. Estas iniciativas são essenciais para o progresso no tratamento de pessoas com transtorno mental.

9. Gonçalves AM, Sena RR. A reforma psiquiátrica no Brasil: contextualização e reflexos sobre o cuidado com o doente mental na família. Rev Lat Am Enferm. 2001; $9(2): 48-55$.

10. Colvero LA, Ide CAC, Rolim MA. A família e doença mental: a difícil convivência com diferença. Rev Esc Enferm USP. 2004;38(2):197-205.

11. Sundeen SJ. Reabilitação psicossocial. In: Stuart GW, Laraia MT. Enfermagem psiquiátrica: princípios e práticas. 6a ed. Porto Alegre: Artmed; 2001. p. 275-94.

12. Delgado JA. A família vivenciando situações de saúdedoença: um conhecimento em construção. In: Elsen I, Marcon SS, Santos MR. O viver em família e sua interface com a saúde e a doença. Maringá: EDUEM; 2002. p. 443-56.

13. Luis MAV. A respeito da asilar exclusão: instituição e desinstitucionalização. In: Jorge MSB, Silva WV, Oliveira $\mathrm{F}$, organizadoras. Saúde mental: da prática asilar ao terceiro milênio. Fortaleza: EDUECE; 1999. p. 13-41.

14. Rocha RM, Bartmann M, Kritz S. Enfermagem em saúde mental. 2a ed. Rio de Janeiro: SENAC; 1996.

15. Waidman MAP, Gusmão R. Família e cronicidade da doença mental: dúvidas, curiosidade e relacionamento familiar. Fam Saúde Desenv. 2001;3(2):154-62. 